Марчук В.І., Гринюк С.В., Марчук І.В., Сачковська Л.О

Луцький національний технічний універсистет

\title{
ДИНАМІЧНА МОДЕЛЬ ПРОЦЕСУ ШЛІФУВАННЯ ПЕРЕРИВЧАСТИМИ КРУГАМИ
}

В роботі розглядається динамічна модель прочесу шліфування переривчастими кругами як об'єкт управління. Динамічна модель переривчастого шиіфування представлясться у вигляді одномасової системи. В прочесі иліфування спостерігається регенеративний ефект, який заключається в тому, що реакція пружної системи проявляється у вигляді зворотнього зв'язку з запізнення у часі. Цей ефект відіграє подвійну роль $i$ значно ускладнює вивчення динаміки процесу шліфування, так як за зносу в прочесі різання круг $і$ деталь задіяні в регенеруючому зворотньому зв'язку. В результаті проведених досліджень отримуємо оптимальний розв'язок для об'єктивного представлення динаміки процесу переривчастого шліфування.

Ключові слова: моделю, амплітуда, шліфування, точність, деталь.

Вступ. Ідея створення переривчастого шліфування складається 3 періодичного переривання контакту круга 3 деталю і виключення теплового насичення поверхневих шарів оброблюваного матеріалу для зменшення температури різання. Характерною особливістю переривчастого шліфування $\epsilon$ самооформлення макро профіля робочих виступів круга. Процес знімання матеріалу в таких умовах відрізняється від звичайного шліфування.

Математична модель процесу шліфуванння як об'єкта управління повинна відображати взаємозв'язок сил різання і регулюючих впливів, враховуючи вплив на динаміку процесу шліфування зносу круга і характеристик пружної системи $[1,7]$.

Огляд та аналіз попередніх досліджень. В процесі шліфування спостерігається регенеративний ефект, який заключається в тому, що реакція пружної системи проявляється у вигляді зворотнього зв'язку з запізнення у часі. Цей ефект відіграє подвійну роль і значно ускладнює вивчення динаміки процесу шліфування, так як за зносу в процесі різання круг i деталь задіяні в регенеруючому зворотньому зв'язку[2, 7-9].

Відомі теоретичні та експерементальні дослідження, що розглядаються в роботах $[3,4,7$ 9], показують, що пружну систему верстата можна з моделювати як багатомассову коливаючу систему 3 присутнім їй характерним спектром власних частот. Деформації пружної ситеми шліфувальних верстатів характерезуються значеннями, які порівнюються 3 величиною припуску, який знімається.Дані переміщення складаються 3 контактних деформацій, які обумовленні наявністю зазорів на стиках зв'язаних вузлів, і деформацій пружної системи, які зв'язані з піддатливістю вузлів станка, пристосувань і деталі [5-9].

Виклад основного матеріалу. Динамічна модель переривчастого шліфування представимо у вигляді одномасової системи «т» зв'язаної з нерухомою опопрою за допомогою пружини «С». На масу «т» діє імпульсне навантаження $F\left(\tau_{1}, \tau_{2}\right)$, де $\tau_{1}$ - період контакту робочого виступу переривчастого круга 3 оброблювальною деталлю, $\tau_{2}$ - період розриву процесу різання при проходженні впадини круга над зоною контакту.

Коливальний рух маси «т» на інтервалі $\left(0, \tau_{1}\right)$ описується диференціальним рівнянням

$$
m \ddot{y}+c y=F_{0},
$$

а на інтервалі $\left(\tau_{1}, \tau_{2}\right)$ рух маси «m» описується рівняннм $(2)$

$$
m \ddot{y}+c y=0 .
$$

Розв'язок рівняння (1) має настпний вигляд

$$
y_{1}=A \sin k \tau+B \cos k \tau+h,
$$


де $k=\sqrt{c / m}-$ власна частота коливання системи;

$h=F_{0} / c-$ статистичне переміщення маси «т» під дією сили $F_{0}$.

Розв'язок рівняння (2) має настпний вигляд

$$
y_{2}=C \sin k \tau+D \cos k \tau \text {. }
$$

Невідомі сталі A,B,C,D визначаються із чотирьох початкових умов

$$
\begin{aligned}
& \left.\begin{array}{l}
y_{1}(0)=y_{2}\left(\tau_{2}\right) \\
\dot{y}_{1}(0)=\dot{y}_{2}\left(\tau_{2}\right)
\end{array}\right\}, \\
& \left.\begin{array}{l}
y_{1}\left(\tau_{1}\right)=y_{2}\left(\tau_{1}\right) \\
\dot{y}_{1}\left(\tau_{1}\right)=\dot{y}_{2}\left(\tau_{1}\right)
\end{array}\right\} .
\end{aligned}
$$

Після розв’язку системи рівнянь і перетворень отримаємо

$$
\begin{gathered}
C=h \cdot \frac{\sin k \frac{\tau_{1}}{2} \cdot \sin k \frac{\tau_{1}+\tau_{2}}{2}}{\sin k \frac{\tau_{2}}{2}}, \\
D=\frac{h \cdot \sin k \frac{\tau_{1}}{2}}{\cos k \frac{2 \tau_{1}+\tau_{2}}{2} \cdot \sin k \frac{\tau_{2}}{2}} \cdot\left(\cos k \frac{\tau_{1}}{2}-\sin k \frac{\tau_{1}+\tau_{2}}{2} \cdot \sin k \frac{2 \tau_{1}+\tau_{2}}{2}\right), \\
A=C \cdot \cos k \tau_{2}-D \cdot \sin k \cdot k \tau_{2}, \\
A=C \cdot \sin k \tau_{2}+D \cdot \cos k \cdot k \tau_{2}-h .
\end{gathered}
$$

При $\sin k \frac{\tau_{2}}{2}=0$ i $\cos k \frac{2 \tau_{1}+\tau_{2}}{2}=0$ константи А,В,С,D прямують до нескінченності. При цих умовах в системі наступає ударний резонанс.

Умови ударного резонансу:

$$
\begin{aligned}
& \text { 1. } \sin k \frac{\tau_{2}}{2}=0 \text { при } k \frac{\tau_{2}}{2}=\pi \cdot n, \\
& \text { де } n=1,2, \ldots, \infty \text { звідки } \tau_{2}=\frac{2 \pi n}{k} ; \\
& \text { 2. } \cos k \frac{2 \tau_{1}+\tau_{2}}{2}=0 \text { при } k \frac{2 \tau_{1}+\tau_{2}}{2}=\frac{\pi}{2}+\pi n, \\
& \text { звідки } \tau_{2}+2 \tau_{1}=\frac{\pi(1+2 n)}{k} .
\end{aligned}
$$

Із отриманих умов (11) і (12) випливає безчислова множина резонансних станів системи. Повний розв'язок диференціальних рівнянь одномасової системи має вигляд [6]

де $S=\int_{0}^{\tau} P(\tau) d \tau-$ імпульс сили;

$$
A=\frac{s}{2 m \sqrt{\frac{c}{m}} \cdot \sin \left(\pi \sqrt{\frac{c}{m}} / \omega\right)},
$$

$P={ }^{c} / m$

$S=F_{0} \tau_{1}$

$F_{0}$ - сила різання, $\mathrm{H}$;

$\omega$ - частота дій імпульсів.

Вираз $\frac{s}{m \cdot \sqrt{c / m}}$ визначає максимальне відхилення, яке викликане однократним імпульсом.

Вираз $\beta=\frac{1}{2 \sin \left(\pi \sqrt{\frac{c}{m}} / \omega\right)}$ характерезує повторення ударів від ріжучих виступів.

(C) Марчук В.І., Гринюк С.В., Марчук І.В., Сачковська Л.О 
При переривчастому шліфування існує безчисленна множина резонансних систем як при $\omega<\sqrt{c / m}$, так і при $\omega>\sqrt{c / m}$. Із рівності (13) видно, що на величину амплітуди вимушених коливань дає вплив імпульс сисли $\mathrm{S}$.

Повтор дій імпульсів вказує менш значний впливна амплітуду. Амплітудою вимушених коливань можна керувати величиною імпульсу сили. Наприклад, із збільшенням швидкості круга, час контакту $\tau_{1}$ зменшується. Відповідно зменшується імпульс сили $S=F_{0} \tau_{1} \mathrm{i}$ амплітуда вимушених коливань.

Із зменшенням амплітуди збільшується фактична глибина входження ріжучих зерен в метал і збільшується товщина зрізу максимально виступаючих зерен. Збільшується ймовірність контакту оброблювального металу з кругомв порівнянні 3 шліфуванням суцільним кругом.

Контакт металу 3 кругом викликає його зношення і робота круга переходить в режим самозаточування. 3 фізичної точки зору зменшення амплітуди означає, що круг не встигає зреагувати на імпульс сисли $\mathrm{S}$ і система отримує переміщення, яке рівне стататистичному такої ж сили $F_{0}$. При цьому, чим менше $\tau$, тим менша амплітуда $\mathrm{A}$.

Із збільшенням глибини входження ріжучих зерен в метал при переривчастому шліфуванні, зростає сила різання. В результаті імпульс сили $S=F_{0} \tau_{1}$ збільшується.

Тоді можна зробити висновок, що при переривчастому шліфуванні сила різання $F_{0}$ більша, чим при суцільному, але із за інертності вимірювальної апаратури підтвердити це експерементально неможливо.

Попередні дані констатують проте, що переривчастість обробки за рахунок динаміки принципово змінює закономірність знімання матеріалу і механізм зношення круга і тим самим дозволяє кардинально розв'язати проблему підтримки високих ріжучих властивостей кругав процесі шліфування.

Переривчастість шліфування забезпечує одночасну високу продуктивність знімання матеріалу i ефективну правку круга i тим самим створює ефект механіки шліфування. 3 врахуванням $T=2 \pi / \omega$ (Т - період часу між двома імпульсами), а також $T=\alpha \tau_{1}\left(\tau_{1}-\right.$ тривалість контакту виступу круга 3 деталлю; $\alpha$ - відношення між періодом імпульсів і тривалістю їх) i $S=F_{0} \tau_{1}$ формулу для розрахунку амплітуди коливань можна представити наступним чином

$$
A=\frac{F_{0} \cdot 2 \cdot \pi \cdot \sqrt{\frac{c}{m}}}{\alpha \cdot \omega \cdot 2 \cdot c \cdot \sin \left(\pi \cdot \sqrt{\frac{c}{m}} / \omega\right)}=\frac{\pi \cdot h \cdot \sqrt{\frac{c}{m}}}{\alpha \cdot \omega \cdot \sin \left(\pi \cdot \sqrt{\frac{c}{m}} / \omega\right)},
$$

де $h=F_{0} / c$ - переміщення круга в радіальному напрямку від дії статистичної сили $F_{0}$. 3 рівності (14) випливає:

1. $A \rightarrow \infty$ при періодчному досягненні $\sin \left(\pi \cdot \sqrt{\frac{c}{m}} / \omega\right) \rightarrow 0$;

2. Амплітуда зменшується із збільшенням частоти імпульсів $\omega$.

Другий висновок дуже важливий, оскільки 3 врахуванням $\omega=\frac{2 \pi}{\tau}=\frac{2 \pi \cdot V_{\mathrm{kp}}}{\left(l_{1}+l_{2}\right)}$ (де $V_{\mathrm{kp} .}-$ швидкість круга; $l_{1}, l_{2}$ - довжини виступів і впадин перривчастого круга), збільшення швидкості круга i зменшення $l_{1}+l_{2}$, тобто довжин впадин і виступів на крузі, частота імпульсів $\omega$ збільшується і приводить до зменшення амплітуди вимушених коливань А. Це вказує на те, що при умові оптимального відношення $\left(\pi \cdot \sqrt{\frac{c}{m}} / \omega\right) \neq 0$, амплітуду коливань А практично можна зменшити до нуля.

Розглянемо процес шліфування деталі, яка рухається по нормалі до робочої поверхні круга (рис. 1). За період входження впадини переривчастого круга деталь перемістилася в радіальному напрямку на величину h. Знімання матеріалу виконають зерна, які розташовані на передній кромці робочого виступа. Внаслідок високого навантаження цих зерен і інтенсивності випадіння із зв'язки, на робочому виступі круга з'явиться фронтальна поверхня довжиною $l$, розташованна під «кутом атаки» $a$ до площини різання. 


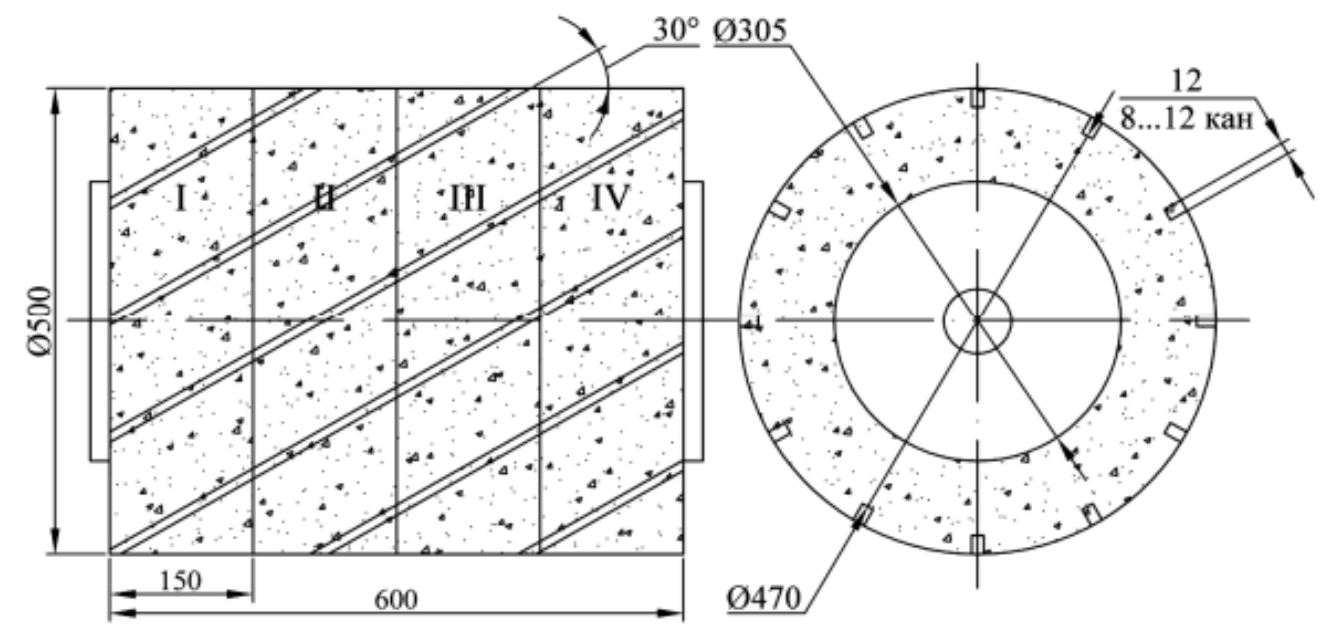

\begin{tabular}{|c|c|c|}
\hline \multirow{2}{*}{ № абразивного диска } & \multicolumn{2}{|c|}{ Зернистість } \\
\cline { 2 - 3 } & Чорнове шліфування & Напівчис тове шліфування \\
\hline I & 80 & 63 \\
\hline II & 63 & 40 \\
\hline III & 32 & 25 \\
\hline IV & 25 & 25 \\
\hline
\end{tabular}

Рис. 1 Розрахункова схема переривчастого шліфування

Збільшення глибини входження матеріалу деталі в робочу поверхню круга, рууйнується зв'язка, круг працює в режимі самозаточування. Забезпечується стабільність ріжучої здатності круга по часу. 3 цього можна зробити висновок проте, що переривчасте шліфування $\epsilon$ новим методом правки круга безпосередньо в процесі шліфування.

Аналіз формули (14) показує, що при збільшенні $\omega$ до визначеного значення відношення $\frac{\pi \cdot \sqrt{\frac{c}{m}}}{\alpha \cdot \omega \cdot 2 \cdot \sin \left(\pi \cdot \sqrt{\frac{c}{m}} / \omega\right)}<1$ і відповідно $A<h$.

Саме в цьому заключається ефект переривчастого шліфування, як нового методу правки круга. При цьому, чим більше $\alpha$, тим кращий результат. Відповідно, ефективність правки круга зростає з зменшенням довжини ріжучого виступу круга.

Після підстановки в рівність (14) значення $\alpha=\frac{l_{1}+l_{2}}{l_{1}} \mathrm{i} \omega=\frac{2 \pi}{\tau}=\frac{2 \pi \cdot V_{\mathrm{kp}}}{\left(l_{1}+l_{2}\right)}$ отримаємо

$$
A=\frac{h \cdot \sqrt{\frac{c}{m} \cdot l_{1}}}{2 \cdot V_{\mathrm{Kp}} \cdot \sin \left(\pi \cdot \sqrt{\frac{c}{m}} / \omega\right)} .
$$

Таким чином, із зменшенням довжини ріжучого виступу $l_{1}$, зменшується амплітуда $\mathrm{A}$.

Висновки. На закінчення можна сказати, що недивлячись на прийняті допущення, отриманий розв'язок (15) дає об'єктивне представлення про динаміку процесу переривчастого шліфування. При динамічному навантаженні системи, маса шлифувального круга $\mathrm{m}$ здійснює гармонічні коливання. Збільшення глибини входження ріжучих зерен створює умови для ударного взаємозв'язку зв'язки круга з металом, що приводить до інтенсивного зносу круга. Відбувається неперервне оновлення ріжучого контура шліфувального круга. Коливання виконують функцію правлячого інструмента. Вони стабілізують гострий ріжучий рельєф круга і відповідно технологічні параметри процесу шліфування: точність, якість поверхневого шару і теплопровідність.

В порівнянні з суцільним шліфуванням, переривчасті круги мають більш високу ріжучу здатність, працюючи в режимі самозаточення, що дозволяє використовувати більш твердих кругів. Для уникнення великих дтнамічних навантажень, амплітуду коливань А потрібно обмежувати. 


\section{Інформаційні джерела}

1. Марчук B.I. Технологічні основи забезпечення якості робочих поверхонь кілець роликопідшипників [Текст] : дис... д-ра техн. наук: 05.02.08 / Марчук Віктор Іванович ; Луцький держ. технічний ун-т. - Луцьк, 2004. - 458 арк.+ дод.: 150арк. - арк. 430-458

2. Перель Л.Я. Подшипники качения: расчет, проектирование и обслуживание опор: [ Справочник ]. - М.: Машиностроение. - 1989. - №4. - С. 130- 134.

3. Ящерицын П.И. Повышение качества шлифованных поверхностей и режущих свойств абразивно-алмазного инструмента / П.И. Ящерицын, А.Г. Зайцев. - Минск : Наука и техника, 1972. $-480 \mathrm{c}$

4. Якимов А.В. Технология машиностроения: Учебник / А.В. Якимов, А.А. Якимов, В.П. Ларшин, В.Н. Свирщев. - Пермь, 2002. -563 с.

5. Лурьє Г.Б. Шлифование металлов. - М.: Машиностроение, 1969. - 172 с.

6. Островский В.И. Теоретические основи процесса шлифования. - Л.: Ленинград. Ун-та, 1981. - 144 c.

7. В.I Марчук, І.В Марчук Технологічне керування температурою під час безцентрового шліфування функціональних поверхонь обертання. Наукові нотатки, 142-147

8. Т.Г Джугурян, В.I Марчук, І.В Марчук, М.В Олексин, ЛО Сачковська. До визначення умов зниження температури безцентрового шліфування переривчастими кругами.Перспективні технології та прилади №13 2018 р, ст48-52.

9. Т.Г. Джугурян, І.В. Марчук. Особливості безцентрового шліфування циліндричних поверхонь функціонального призначення переривчастими шліфувальними кругами. Перспективні технології та прилади, 115-118

\section{Marchuk V.I., Hryniuk S.V., Marchuk I.V., Sachkovskaya L.O. Lutsk National Technical University}

\section{DYNAMIC MODEL OF GRINDING CIRCUIT GRINDING PROCESS}

The paper considers a dynamic model of the process of grinding with discontinuous wheels as an object of control. The dynamic model of intermittent grinding is presented in the form of a singlemass system. During the grinding process, a regenerative effect is observed, which is that the reaction of the elastic system manifests itself in the form of feedback from the delay in time. This effect plays a dual role and significantly complicates the study of the dynamics of the grinding process, as wear and tear during the cutting process, the circle and the part are involved in the regenerative feedback. As a result of the research, we obtain the optimal solution for an objective representation of the dynamics of the process of intermittent grinding.

Keywords: model, amplitude, grinding, accuracy, detail.

Марчук В.И., Гринюк С.В., Марчук И.В., Сачковська Л.А.

Луцкий национальный технический университет

\section{ДИНАМИЧЕСКАЯ МОДЕЛЬ ПРОЦЕССА ШЛИФОВАНИЕ ПРЕРИВИСТАМИ} КРУГАМИ

В работе рассматривается динамическая модель прочесса шлифования прерывистыми кругами как объект управления. Динамическая модель прерывистого иллифования представляется в виде одномассовой системы. В проиессе илифовки наблюдается регенеративный эффект, который заключается в том, что реакиия упругой системь проявляется в виде обратной связи с опоздание во времени. Этот эффект играет двойную роль и значительно затрудняет изучение динамики прочесса шлифования, так как за износа в проиессе резки круг и деталь задействованы в регенерирующем обратной связи. В результате проведенных исследований получаем оптимальное решение для объективного представления динамики проиесса прерывистого шлифования.

Ключевые слова: модель, амплитуда, илифование, точность, деталь. 